\title{
Storability of some apricot varieties as affected by storage period
}

\author{
Ezzat, A.1, Nyéki, J. ${ }^{1}$, Soltész, M. ${ }^{1}$, Amriskó, L. ${ }^{2}$, Balázs, G. ${ }^{3}$, \\ Mikita, T. ${ }^{2}$ \& Szabó, Z. ${ }^{1}$ \\ ${ }^{1}$ University of Debrecen, Institute of Horticulture, 4032 Debrecen, Böszörményi út 138. \\ ${ }^{2}$ NORTHCOT Ltd, 3885 Boldogköváralja \\ ${ }^{3}$ GYÜMÖLCSÉRT Ltd, 3885 Boldogköváralja
}

\begin{abstract}
Summary: the aim of this study was the estimation of storability of 10 apricot varieties in regard to percentage fruit weight loss, firmness, acidity and T.S.S in fruit during storage periods from one week to 4 weeks. All the variety gave the same trend as all of them loss weight, firmness decreased, acidity and T.S.S decreased but the differences were not the same in all varieties. in case of some varieties the percentage of fruit weight loss reached to about $9 \%$ after 28 days also the differences between varieties in two seasons refer that this character is determined by genetic factors beside effect of environmental and agriculture factors.
\end{abstract}

Key words: Apricot fruit quality, firmness, acidity and T.S.S.

\section{Introduction}

Apricot (Prunus armeniaca L.) is classified under the Prunus species of Prunoidae sub-family of the Rosaceae family of the Rosales group. This type of fruit is a cultivated type of zerdali (wild apricot) which is produced by inoculation (Ozbek, 1978).

Apricot has an important place in human nutrition, and can be used as fresh, dried or processed fruit Apricot has alimited post harvest life becuase of its high moisure content and metabolic activities that take place during post harvest phase. It is fragile fruit having short storage life (3-5 days) at ambient condition, 2-4 weaks at cold storage, according to cultivar. The short storage life of this fruit is due to short time period from commercial rippening to the degradation process characteristic like senescence (1).

Apricot quality is dramatically affected by the harvest date. Consumer is often dissatisfied of apricot because of lack of aroma, not perfect ripeness, too firm or too soft texture. Beauty and taste are the features required by the consumer. Beauty is defined by integrity, proportion, and clearness. Proportion and integrity are characteristics which can be referred to apricot quality (Mencarelli et al., 2006)

It is generally agreed that apricot quality is highly dependent on the maturity stage at harvest. Nevertheless, for commercial reasons (handling, long-distance transport), for example Bergeron apricot is generally harvested at an early stage of maturity and stored at low temperature $\left(1-2{ }^{\circ} \mathrm{C}\right)$ for up to 3 weeks. Because the formation of the volatile compounds in this fruit is a dynamic process, the typical flavour of apricot is generally not present at harvest but develops after a ripening process. Nevertheless, this postharvest maturation stage is rarely carried out under optimal conditions and generally, consumers often complain about the poor quality of Bergeron, incriminating its lack of both sugar and aroma (Bruhn et al., 1991; Guillot et al., 2003; Mencarelli, Botondi, De Santis, \& Vizovitis, 2006).

Apricot (Prunus armeniaca L.) is a stonefruit species producing a climacteric fruit with a short shelf life. Fruit ripening involves several processes including metabolic changes, colour shift and softening, which in the main apricot cultivars causes postharvest deterioration that limits the shelf life of the fruit. The loss of firmness occurring during ripening is considered the key factor limiting this deterioration. In order to extend the postharvest period, the fruit is sometimes harvested before ripening and in spite of its climacteric nature it never reaches the optimal quality attributes for consumers (Carmen et al., 2011).

The aim of this work was to investigate the changes in physicochemical properties of 10 apricot varieties and stored at $+3{ }^{\circ} \mathrm{C}$ for up to 4 weeks.

\section{Materials and methods}

This study investigated the effect of storage temperature $\left(3{ }^{\circ} \mathrm{C}\right)$ and duration $(1,2,3$ and 4 weeks) on fruit quality of 'Goldstrike, Goldbar, Gold Cot, Bergarouge, Flavor Cot, Bergarouge,Bergeron, Jumbo Cot, Robada, Tom Cot and Sweet Cot apricot cultivars grown in Hungary.

The present investigation was carried out for two successive seasons 2010 and 2011 in Boldogkőváralja, Hungary. Fruits of Goldstrike, Goldbar, Gold Cot, Bergarouge, Flavor Cot, Bergarouge, Bergeron, Jumbo Cot, Robada, Tom Cot and Sweet Cot were considered in each season. Trees were seven years old. They were spaced at $5 \times 5$, 
vase trained and subjected to recommebded cultural practices.

Fruit chosen for this study were uniform in size, color and weight also were immediately transported to the pomology laboratory and started storage treatment as 90 fruit per varieties is used. We did all the measurment on about 10 fruits after harvest immediately thin other fruits were stored at $3{ }^{\circ} \mathrm{C}$ for $7,14,21$ and 28 days and after each period the fruit subjected to all measurements to assess the effect of treatments on fruit quality. The following parameters were determined after cold storage: weight loss (\%), according to Mccarmack and broom (2), fruit firmness (Ib/inch2) by Magnaes, juice TSS\% by hand refractometer and juice acidity $(\%)$.

\section{Results and discussion}

Data in table (1) shows that the percentage of fruit weight loss of all tested varieties increase with prolongs of storage period and this result was agreed with (Mencarelli et al. 2006). The bigest reduction was after 28 days of storage in all varieties. In regard to differences between varieties, it is clear

Table 1: Percentage of fruit weight loss of 10 apricot varieties throught 7 , 14, 21 and 28 days in 2010 and 2011 seasons

\begin{tabular}{|c|c|c|c|c|c|}
\hline \multicolumn{6}{|c|}{ Weight loss (\%) } \\
\hline \multicolumn{6}{|c|}{2010 season } \\
\hline \multirow{2}{*}{ Varieties } & \multirow{2}{*}{$\begin{array}{c}\text { Harvest } \\
\text { weight }(\mathrm{g})\end{array}$} & \multicolumn{4}{|c|}{ Storage period } \\
\hline & & 7 Days & 14 Days & 21 Days & 28 Days \\
\hline Goldstrike & 77.4 & 1.07 & 1.97 & 2.75 & 2.65 \\
\hline Goldbar & 63.3 & 1.54 & 2.41 & 1.58 & 5.01 \\
\hline Gold Cot & 48.3 & 2.02 & 3.98 & 6.52 & 7.13 \\
\hline Flavor Cot & 42.3 & 1.06 & 2.84 & 4.67 & 6.59 \\
\hline Bergarouge & 67.2 & 1.56 & 3.05 & 5.66 & 6.92 \\
\hline Bergeron & 47.2 & 1.59 & 4.56 & 5.09 & 5.45 \\
\hline Jumbo Cot & 90.3 & 1.55 & 2.71 & 4.13 & 5.48 \\
\hline Robada & 65.7 & 1.22 & 2.63 & 6.89 & 7.81 \\
\hline Tom Cot & 57.5 & 1.74 & 2.74 & 3.61 & 4.32 \\
\hline Sweet Cot & 58.9 & 1.65 & 3.77 & 7.19 & 8.16 \\
\hline \multicolumn{6}{|c|}{2011 season } \\
\hline Goldstrike & 55.2 & 1.81 & 2.66 & 1.81 & 1.47 \\
\hline Goldbar & 54.1 & 2.59 & 3.79 & 1.85 & 6.10 \\
\hline Gold Cot & 44.3 & 2.20 & 2.25 & 3.50 & 4.29 \\
\hline Flavor Cot & 48.8 & 1.43 & 2.15 & 2.20 & 5.02 \\
\hline Bergarouge & 47.8 & 1.57 & 1.78 & 3.45 & 2.09 \\
\hline Bergeron & 32.7 & 2.37 & 4.05 & 4.20 & 3.06 \\
\hline Jumbo Cot & 63.1 & 1.31 & 2.14 & 1.58 & 5.74 \\
\hline Robada & 50.2 & 6.83 & 3.49 & 4.26 & 8.20 \\
\hline Tom Cot & 40.9 & 2.44 & 4.22 & 7.82 & 9.84 \\
\hline Sweet Cot & 51.9 & 5.45 & 3.89 & 6.63 & 6.64 \\
\hline
\end{tabular}

that the following varieties, Sweet Cot, Robda, Gold, Flavor Cot and Berarouge gave the highest percentage of fruit weight loss after 28 days as 8.2, 7.8, 7.1, 6.9 and 6.6, respectively in season 2010. Meanwhile in 2011 season these verities gave different trend.

In regard to fruit firmness, during fruit ripening a loss of firmness occurs, which is a key factor limiting postharvest life, a wide range of fruit firmness at commercial maturity has been observed in different cultivars (Carmen et al., 2011).

So the data in table 2 showed that the firemness reduce by prolong of storage period. Concerning the differences between varieties, there are no big differences between varieties after harvest but the varieties taked different trend after storage as we notice from data that the Robada, Tom Cot and Goldbar gave the high firmness after harvest and after storage for 28 days in season 2010.

This trend was different in 2011 season as Bergarouge, Bergaron and Jumbocot were the highest in firmness as they gave 8.6, 8.5 and $8.4(\mathrm{Ib} / \mathrm{inch} 2)$ respectivally.

In addition, it is clear from data in table 3 and 4 that the acidity and T.S.S is differ between varieties at harvest and get to reduce by storage but ther are no big differences between varieties.

Table 2: Fruit firmness of some apricot varieties as affected by storage for 7, 14, 21 and 28 days in 2010 and 2011 seasons

\begin{tabular}{|c|c|c|c|c|c|}
\hline \multicolumn{6}{|c|}{ Firmness(Ib/inch2) } \\
\hline \multicolumn{6}{|c|}{2010 season } \\
\hline \multirow{2}{*}{ Varieties } & \multirow{2}{*}{$\begin{array}{l}\text { Harvest } \\
\text { firmness }\end{array}$} & \multicolumn{4}{|c|}{ Storage period } \\
\hline & & 7 Days & 14 Days & 21 Days & 28 Days \\
\hline Goldstrike & 7.3 & 7.0 & 6.1 & 6.1 & 5.5 \\
\hline Goldbar & 8.0 & 7.1 & 7.0 & 6.1 & 5.8 \\
\hline Gold Cot & 7.5 & 6.8 & 6.7 & 6.3 & 6.1 \\
\hline Flavor Cot & 7.2 & 7.1 & 6.6 & 6.1 & 5.6 \\
\hline Bergarouge & 6.4 & 6.0 & 5.2 & 5.2 & 4.6 \\
\hline Bergeron & 7.3 & 6.8 & 5.9 & 5.4 & 5.2 \\
\hline Jumbo Cot & 7.3 & 6.4 & 6.3 & 6.2 & 5.9 \\
\hline Robada & 8.4 & 7.0 & 6.2 & 5.1 & 4.8 \\
\hline Tom Cot & 8.4 & 7.3 & 6.3 & 5.6 & 5.6 \\
\hline Sweet Cot & 7.5 & 6.9 & 6.3 & 5.8 & 5.3 \\
\hline \multicolumn{6}{|c|}{2011 season } \\
\hline Goldstrike & 7.6 & 7.0 & 6.2 & 6.0 & 5.7 \\
\hline Goldbar & 7.9 & 6.3 & 6.0 & 5.7 & 5.3 \\
\hline Gold Cot & 7.3 & 7.0 & 6.8 & 6.0 & 5.3 \\
\hline Flavor Cot & 6.9 & 6.1 & 5.7 & 6.2 & 5.5 \\
\hline Bergarouge & 8.6 & 7.5 & 7.0 & 6.7 & 6.0 \\
\hline Bergeron & 8.5 & 7.6 & 7.1 & 6.2 & 5.4 \\
\hline Jumbo Cot & 8.4 & 7.4 & 7.0 & 6.4 & 5.2 \\
\hline Robada & 6.0 & 5.8 & 5.5 & 5.0 & 4.7 \\
\hline Tom Cot & 6.5 & 6.0 & 5.8 & 5.4 & 5.0 \\
\hline Sweet Cot & 8.0 & 7.7 & 7.5 & 6.9 & 5.3 \\
\hline
\end{tabular}


Table 3: Fruit acidity of some apricot varieties as affected by storage for 7 , 14, 21 and 28 days in 2010 and 2011 seasons

\begin{tabular}{|c|c|c|c|c|c|}
\hline \multicolumn{6}{|c|}{ Acidity (\%) } \\
\hline \multicolumn{6}{|c|}{2010 season } \\
\hline \multirow{2}{*}{ Varieties } & \multirow{2}{*}{$\begin{array}{c}\text { Fruit } \\
\text { acidity at } \\
\text { harvest } \\
(\%)\end{array}$} & \multicolumn{4}{|c|}{ Storage period } \\
\hline & & 7 Days & 14 Days & 21 Days & 28 Days \\
\hline Goldstrike & 1.80 & 1.76 & 1.73 & 1.60 & 1.55 \\
\hline Goldbar & 1.82 & 1.73 & 1.71 & 1.62 & 1,56 \\
\hline Gold Cot & 1.80 & 1.73 & 1.70 & 1.63 & 1.60 \\
\hline Flavor Cot & 1.82 & 1.75 & 1.72 & 1.60 & 1.53 \\
\hline Bergarouge & 1.81 & 1.80 & 1.73 & 1.69 & 1.58 \\
\hline Bergeron & 1.86 & 1.77 & 1.70 & 1.62 & 1.59 \\
\hline Jumbo Cot & 1.82 & 1.78 & 1.71 & 1.66 & 1.53 \\
\hline Robada & 1.79 & 1.76 & 1.69 & 1.67 & 1.60 \\
\hline Tom Cot & 1.87 & 1.75 & 1.67 & 1.62 & 1.53 \\
\hline Sweet Cot & 1.80 & 1.78 & 1.72 & 1.69 & 1.60 \\
\hline \multicolumn{6}{|c|}{2011 season } \\
\hline Goldstrike & 1.79 & 1.78 & 1.75 & 1.63 & 1.55 \\
\hline Goldbar & 1.73 & 1.70 & 1.70 & 1.65 & 1.60 \\
\hline Gold Cot & 1.82 & 1.80 & 1.76 & 1.67 & 1.55 \\
\hline Flavor Cot & 1.82 & 1.81 & 1.75 & 1.70 & 1.57 \\
\hline Bergarouge & 1.80 & 1.77 & 1.73 & 1.73 & 1.62 \\
\hline Bergeron & 1.79 & 1.76 & 1.72 & 1.72 & 1.57 \\
\hline Jumbo Cot & 1.78 & 1.70 & 1.70 & 1.67 & 1.53 \\
\hline Robada & 1.80 & 1.74 & 1.73 & 1.66 & 1.57 \\
\hline Tom Cot & 1.76 & 1.74 & 1.71 & 1.63 & 1.59 \\
\hline Sweet Cot & 1.82 & 1.78 & 1.70 & 1.66 & 1.59 \\
\hline
\end{tabular}

From all above results it clear that many of apricot characters is a genetic determinants and also the environmental and agriculture play vital role in storability of fruit as Paunović (1987) studied the inheritance of fruit characteristics in several apricot lines, he found fruit shape was a very stable, heritable character, fruit flavor appeared to be a variable character, flesh consistency was judged to be a well-inherited character, other characters, such as flesh color, over color and ease-of-picking, were found to be stable, heritable characteristics, fruit weight was judged to be a variable character.

\section{Conclusion}

This study may indicate that the varieties take different trends in behaviour of storage ability and this refer to diffrences in genetic character beside environmental and agriculture treatment preharvest.
Table 4: Fruit T.S.S of some apricot varieties as affected by storage for 7 , 14, 21 and 28 days in 2010 and 2011 seasons.

\begin{tabular}{|c|c|c|c|c|c|}
\hline \multicolumn{6}{|c|}{ TSS (\%) } \\
\hline \multicolumn{6}{|c|}{2010 season } \\
\hline \multirow{2}{*}{ Varieties } & \multirow{2}{*}{$\begin{array}{c}\text { TSS at } \\
\text { harvest } \\
(\%)\end{array}$} & \multicolumn{4}{|c|}{ Storage period } \\
\hline & & 7 Days & 14 Days & 21 Days & 28 Days \\
\hline Goldstrike & 12.1 & 12.0 & 11.6 & 11.0 & 10.5 \\
\hline Goldbar & 10.5 & 09.9 & 09.7 & 09.5 & 09.2 \\
\hline Gold Cot & 12.0 & 11.4 & 10.2 & 09.5 & 09.0 \\
\hline Flavor Cot & 13.5 & 11.5 & 10.9 & 10.0 & 09.7 \\
\hline Bergarouge & 14.5 & 12.4 & 11.3 & 10.3 & 09.8 \\
\hline Bergeron & 10.2 & 09.9 & 09.4 & 09.0 & 08.6 \\
\hline Jumbo Cot & 09.9 & 09.4 & 09.2 & 08.7 & 08.2 \\
\hline Robada & 11.2 & 10.5 & 10.0 & 09.8 & 09.3 \\
\hline Tom Cot & 13.3 & 12.9 & 11.9 & 10.3 & 09.9 \\
\hline Sweet Cot & 13.6 & 13.0 & 12.0 & 11.5 & 10.5 \\
\hline \multicolumn{6}{|c|}{2011 season } \\
\hline Goldstrike & 11.8 & 11.2 & 11.0 & 10.7 & 09.9 \\
\hline Goldbar & 12.3 & 11.1 & 10.8 & 09.9 & 09.4 \\
\hline Gold Cot & 13.5 & 12.9 & 12.5 & 12.0 & 10.3 \\
\hline Flavor Cot & 11.9 & 11.2 & 10.3 & 10.0 & 09.5 \\
\hline Bergarouge & 12.7 & 12.1 & 11.2 & 10.7 & 09.9 \\
\hline Bergeron & 13.0 & 12.9 & 11.8 & 10.3 & 10.0 \\
\hline Jumbo Cot & 12.4 & 11.4 & 10.7 & 10.2 & 09.6 \\
\hline Robada & 11.3 & 10.8 & 10.0 & 09.9 & 09.2 \\
\hline Tom Cot & 12.4 & 11.8 & 11.0 & 10.6 & 09.9 \\
\hline Sweet Cot & 11.0 & 10.5 & 10.0 & 09.9 & 09.3 \\
\hline
\end{tabular}

\section{Acknowledgement}

Research was sponsored by NFU TECH-08-A3/2-20080373 grant.

\section{References}

Bruhn, C. M., Feldman, N., Garlitz, C., Harwood, J., Ivans, E., Marshall, M. et al. (1991). Consumer perceptions of quality: Apricots, cantaloupes, peaches, pears,strawberries, and tomatoes. Journal of Food Quality, 14: 187-195.

Carmen L., Gabino R., José S., Bernardita P., Gerardo L., Carlos H. and María L. (2011). Identification and genetic characterization of an ethylene-dependent polygalacturonase from apricot fruit. Postharvest Biology and Technology, 62: 26-34.

Guillot, S., Boulanger, R., Crouzet, J., Bureau, S., Lepoutre, J. P. \& Galindo, S. (2003). Tracers of apricot aromatic quality. [In J. 
L. Le Quéré \& P. X. Etiévant (Eds.), Flavour research at the dawn of the twenty-first century.] Proceedings of the 10th Weurman Flavour Research Symposium, 606-609.

Krška, B. Pramuková, J. and Vachůn M. (2009): Inheritance of some pomological traits in Minaret $\times$ Betinka apricot progeny. Hort. ScI. (PraguE), 36, (3): 85-91.

Mencarelli, F., Botondi, R., De Santis, D. \& Vizovitis, K. (2006). bost-harvest quality maintenance of fresh apricots. Acta Hort., 701: 503-510.
Mencarelli, F., Botondi, R., De Santis, D. \& Vizovitis, K. (2006). Post-harvest quality maintenance of fresh apricots. In J. M. Audergon (Ed.), Proceedings of the XII international symposium on apricot culture and decline. Acta Horticulturae. 701: 503-510.

Ozbek, S. (1978). Special Horticulture. C . U. Faculty of Agriculture no. 128, Adana, Turkey

Paunovič S.A. (1987). The Study of Inheritance in apricot and Peach Progenies. Acta University of Agricultural Faculty of Horticulture, 2: 109-124. 